\title{
Synthesis of the mesostructured polymer-silica composite and silicon dioxide through polymer swelling in silica precursor
}

\author{
P. Krasucka ${ }^{1}$ J. Goworek ${ }^{1}$ A. Kierys ${ }^{1}$
}

Received: 15 October 2015/Revised: 23 December 2015/Accepted: 28 December 2015/Published online: 5 January 2016

(c) The Author(s) 2016. This article is published with open access at Springerlink.com

\begin{abstract}
Tetrabutoxysilane (TBOS) transition introduced into the preformed porous polymer was found as an effective method in the preparation of highly porous silica adsorbents. The swelling of the acrylic polymer XAD7HP in TBOS causes the total infiltration of polymer beads by the silica precursor. Transformation of TBOS in aqueous solution at presence of the surfactant (hexadecyltrimethylammonium bromide, CTAB) produces two composite phases: silica-polymer beads and fine silica-CTAB particles. After their calcination, two pure silica phases exhibiting extremely high porosity were obtained. The paper presents the structural properties of the composites and silica materials. All materials were characterized by scanning and transmission electron microscopy (SEM and TEM), the low temperature nitrogen adsorption, X-ray diffraction (XRD) and ${ }^{29} \mathrm{Si}$ NMR spectroscopy.
\end{abstract}

Keywords XAD7HP polymer - Silica spheres - CTAB · Metronidazole

\section{Introduction}

Porous silica materials with the large specific surface area, high pore volume and tunable pore size are of great interest for academia and industry due to their applications in adsorption, catalysis (Udayakumar et al. 2005; Nejat et al. 2015), separation processes (Sepehrian et al. 2009), drug

A. Kierys

agnieszka.kierys@umcs.lublin.pl

1 Department of Adsorption, Faculty of Chemistry, Maria Curie-Sklodowska University, 3 M. Curie-Sklodowska, Sq., 20-031 Lublin, Poland delivery systems (Kwon et al. 2013; Vallet-Regi et al. 2007) and gas storage (Menon and Komarneni 1998; Ramachandran et al. 2007). The possibility of using polymer-silica composites to tailor the textural properties of silica could potentially be of considerable value for new silica applications within above mentioned fields of interest (Kierys et al. 2014; Acosta et al. 2014). Many factors influence the formation of siliceous network, including the $3 \mathrm{D}$ configuration of $\mathrm{SiO}_{2}$ tetrahedra. The main parameters playing a substantial role in condensation of silica species are temperature, concentration of substrates (Stober et al. 1968; Bogush et al. 1988), pH of solution, ageing time and stirring of reacting components (Rahman et al. 2007; Fuchigami et al. 2008). The performance of silica materials in many applications requires controlling their morphology and the pore structure. Such a control of morphology can be achieved by the use of organic templates of nano- or micrometer dimensions (Chang-Chien et al. 2006; Krasucka et al. 2015). Pore structure may be additionally tailored by matching the parameters that influence nucleation and growth of primary silica particles.

Of great importance is the dosage of silica source to aqueous solution containing catalyst causing its further transformation (Fuchigami et al. 2008). Conventionally, the small droplets of silane are added to the reacting mixture during intensive stirring. The distribution of microparticles of the liquid silane in the solution is rather accidental. This may be the reason of some problems with the reproducibility of the final material; additionally, it influences the mechanism of silica species condensation. The rate of hydrolysis depends on the dimensions of particles of the initial silica source, and, consequently, the surface in contact with the solution. As the hydrolysis starts, it first takes place on the surface of the particles and, subsequently, moves towards their interior. The silicic acid, 
produced due to hydrolysis, condenses on the external surface even if the silica precursor hydrolysis is not totally completed in the interior. The hydrolysis and agglomeration of primary particles influence the morphology of the final silica materials. The dosage of silica precursor in molecular form into reacting mixture in one time seems to be impossible.

Recently, we used a substantially different supplying of the silica source into the reacting mixture (Kierys et al. 2010, Krasucka et al. 2015). The approach depends on the initial entrapment of tetraalkoxysilane (TEOS) in porous polymer particles followed by transformation of TEOS into silica in aqueous solution of desired $\mathrm{pH}$. A polymer of high mesoporosity, Amberlite XAD7HP, was used as a support. The main feature of this approach is the ability to yield the polymer-silica composite and the pure porous silica, both of high porosity and high adsorption capacity. The spherical shape of initial polymer beads determined in advance the shape of composite particles as well as the silica obtained from the composite after elimination of the polymer component.

Here, we describe the results on the application of this procedure to modified system containing surfactant. At the absence of surfactant, as in our previous experiment, the tetraethoxysilane entrapped in polymer pores was transformed into $\mathrm{SiO}_{2}$ inside particles without transfer into solution (Kierys et al. 2010). There was no evidence of silica particles formation in the bulk solution, suggesting that the whole silica source is entrapped within polymer pores. In the current study, we present a further discussion of the hard templating method for the synthesis of mesoporous silica in the presence of the surfactant. The surfactant adsorbs on polymer beads saturated with silica precursor and, due to the adsorption competition, excludes, the silica precursor toward the bulk solution. The purpose of this paper is to address the question of how the addition of surfactant influences the equilibrium of the reacting mixture. Moreover, in the present study, the influence of alkyl constituent of silane TEOS or TBOS on the porosity of mixed silica products is discussed.

\section{Experimental}

\subsection{Materials}

Amberlite XAD7HP (Rohm \& Haas), CTAB (hexadecyltrimethylammonium bromide) and metronidazole were obtained from Sigma Aldrich. tetrabutoxysilane (TBOS) was received from Fluka. The silica gel $40(\mathrm{Si}-40)$ was from Merck. $\mathrm{NH}_{4} \mathrm{OH}(25 \%)$ and $\mathrm{HCl}(35-38 \%)$ were obtained from $\mathrm{POCH}$ (Poland). All reagents were analytical grade. Before the use, Amberlite XAD7HP was washed with deionized water and dried in $80{ }^{\circ} \mathrm{C}$ under vacuum.

\subsection{Sample preparation}

Amberlite XAD7HP (the porous polymer supplied in the form of insoluble, white beads) was first wetted with the silica precursor TBOS (1.85 g TBOS/1 g XAD7) until all the polymeric beads were swollen. Subsequently, the beads swollen in TBOS were left for $48 \mathrm{~h}$ to facilitate the full penetration of the polymer pore system with silica precursor. Afterwards, the sample saturated with TBOS was immersed in the aqueous solution of CTAB at the presence of $\mathrm{NH}_{4} \mathrm{OH}$ as an agent regulating the solution $\mathrm{pH}$ and catalyzing silica condensation process. The molar composition of the reacting mixture was 0.0066:0.048: 0.558:6.67 for CTAB/TBOS/ $/ \mathrm{NH}_{4} \mathrm{OH}(25 \%) / \mathrm{H}_{2} \mathrm{O}$, respectively. The synthesis was conducted in dynamic conditions under rigorous stirring of the reacting mixture for about $3 \mathrm{~h}$. The obtained reacting mixture was left for $72 \mathrm{~h}$ at room temperature. The solution over the beads becomes increasingly milky over the course of 3 days, which indicates the precipitation of a new phase containing fine silica particles. The solid product obtained in the flask consists of relatively large spherically-shaped particles of the polymer$\mathrm{SiO}_{2}$ composite and very fine particles formed in the bulk solution. Both phases were separated using the sieve ( $\mathrm{Ny}$ lon sieve with $0.150 \mathrm{~mm}$ sieve openings). Separation was easy due to the large difference between particle dimensions with their size within the range from 0.20 to $0.5 \mathrm{~mm}$ for composite beads and ca. 10 microns for the fine phase. Subsequently, portions of both products were calcined at $550{ }^{\circ} \mathrm{C}$ for $10 \mathrm{~h}$. Finally, we obtained two white siliceous samples, i.e. large spheres obtained after calcination of the composite (labelled as $\mathrm{T}-\mathrm{SiO}_{2}$ ) and powder of MCM-41 type (Beck et al. 1992) (named as MCM-B). Figure 1 depicts a general strategy for the synthesis of $\mathrm{T}-\mathrm{SiO}_{2}$ and MCM-B silicas.

\subsection{Adsorption of metronidazole}

The adsorption experiment was performed by immersing $0.1 \mathrm{~g}$ of the $\mathrm{T}-\mathrm{SiO}_{2}$ in $7 \mathrm{~cm}^{3}$ of aqueous solutions of metronidazole of known initial concentration ranging from 0.024 to $0.1 \mathrm{mmol}$ per $1 \mathrm{dm}^{3}$. For comparative purposes, the adsorption behavior of the $\mathrm{Si}-40$ silica gel (35-70 Mesh) was studied. The system was equilibrated at room temperature, under static conditions, for $24 \mathrm{~h}$. The concentration of the drug in the adsorption equilibrium was measured by UV-VIS spectrophotometer (Varian 100 Bio Carry) at $319 \mathrm{~nm}$. 


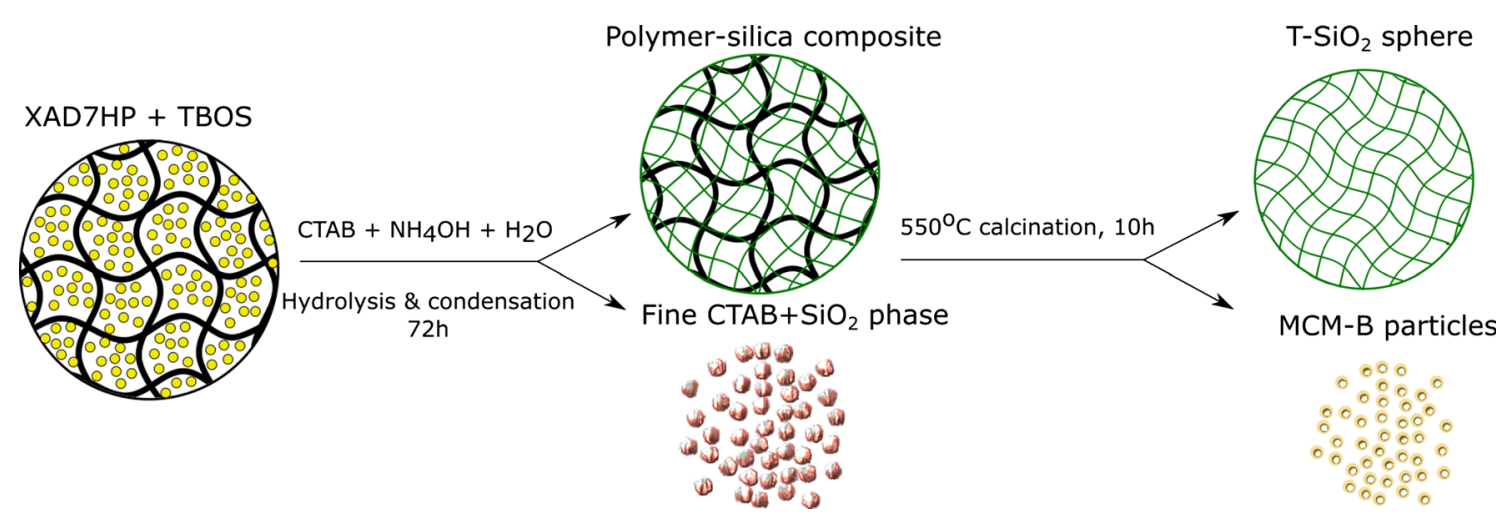

Fig. 1 Scheme for the synthesis of siliceous samples obtained by the hard templating route

\subsection{Characterization methods}

The morphology of the silica samples were examined with the use of scanning electron microscope (FEI Quanta 3D FEG) working at $5 \mathrm{kV}$. The transmission electron microscope (TEM) studies were conducted on a Titan $3^{\text {TM }}$ G2 60e300 microscope (FEI Company USA).

Powder X-ray diffraction was used to characterize the structure of silica samples. The measurements were performed with PANalytical apparatus Empyrean (Netherlands 2012) using $\mathrm{CuK} \alpha$ radiation with $\lambda=1.5418 \AA$.

The adsorption/desorption isotherms of nitrogen at $-196{ }^{\circ} \mathrm{C}$ were measured with a volumetric adsorption analyzer ASAP 2405 (Micromeritics, Norcros, USA). The specific surface area, $\mathrm{S}_{\mathrm{BET}}$, was calculated from the linear form of the BET equation in the relative pressure range from 0.05 to 0.25 . The pore size distribution (PSD) was calculated in the standard manner by using the BJH method (Barrett et al. 1951).

${ }^{29} \mathrm{Si}$ magic-angle spinning (MAS) NMR spectra of $\mathrm{T}-\mathrm{SiO}_{2}$ and $\mathrm{Si}-40$ silicas were obtained at the resonance frequency of $59.6 \mathrm{MHz}$ on a Bruker Avance-300 spectrometer. About 8000 scans were applied until a satisfactory signal-to-noise ratio was achieved. The chemical shifts are given in $\mathrm{ppm}$ and referred to $\mathrm{Q}_{8} \mathrm{M}_{8}$ as standard material.

\section{Results and discussion}

The investigated materials were obtained in the following stages of the preparation procedure: the pure polymer beads - the polymer- $\mathrm{SiO}_{2}$ composite, and, finally, pure silica phases i.e. $\mathrm{T}-\mathrm{SiO}_{2}$ and $\mathrm{MCM}-\mathrm{B}$. For these materials (except for MCM-B) the regularity of spherical shape of particles is maintained. However, their size is differentiated in the diameter, i.e. the diameter of polymer- $\mathrm{SiO}_{2}$ composite beads is much larger than the initial XAD7HP beads
(Krasucka et al. 2016); whereas the diameter of $\mathrm{T}-\mathrm{SiO}_{2}$ is smaller than that of the composite but larger than the initial polymer template (Fig. 2a, d). Only MCM-B is in the form of aggregates of fine particles. SEM images presented in Fig. 2e, f, g show that the $\mathrm{T}-\mathrm{SiO}_{2}$ spheres obtained after calcination are totally filled with $\mathrm{SiO}_{2}$. The silica component condenses inside polymer beads and also on their outer surface. The presence of silica within polymer beads interior testifies their total penetration by TBOS molecules. This seems to be obvious due to high porosity of the polymer containing interconnected mesopores. SEM images at higher magnification also confirm differences between the interior structure of the polymer- $\mathrm{SiO}_{2}$ composite bead and the $\mathrm{T}-\mathrm{SiO}_{2}$ sphere, as well as MCM-B particles (Fig. 2).

The formation of both silica phases in the bulk solution is determined by $\mathrm{pH}$ of the reacting mixture as well as by its chemical character. The mass transfer of TBOS from the polymer beads to the bulk solution depends on the thickness of the boundary layer surrounding the spheres; and this layer is affected by fluid velocity around the bead. The progress in hydrolysis and condensation was observed on the basis of the appearance of fine particles out of polymer beads which sediments at the bottom of the flask together, with composite spheres. It may be assumed that the rate of hydrolysis and nucleation is not the same in the bulk solution and in pores of the polymer due to different diffusion of reacting components in these places. It may be expected that the time of hydrolysis inside the pores is longer than in the bulk solution.

In 'free space' in the bulk solution, the hydrolysis and the condensation rate of silane is determined by the rate of mixing of the silica source with aqueous solution of the desired $\mathrm{pH}$ and allows the modeling of the structure of produced silicas. In our experiment, the substrate mixing is controlled by appearance of the silane in the solution, and this process is a result of the competition between molecules of the silica precursor and CTAB for the polymer 
Fig. 2 SEM images of the polymer- $\mathrm{SiO}_{2}$ composite (a), the polymer- $\mathrm{SiO}_{2}$ composite interior $(\mathbf{b}, \mathbf{c})$, the $\mathrm{T}-\mathrm{SiO}_{2}$ sphere (d), and the $\mathrm{T}-\mathrm{SiO}_{2}$ interior (eg), and aggregates of MCM-B fine particles $(\mathbf{h}, \mathbf{i})$
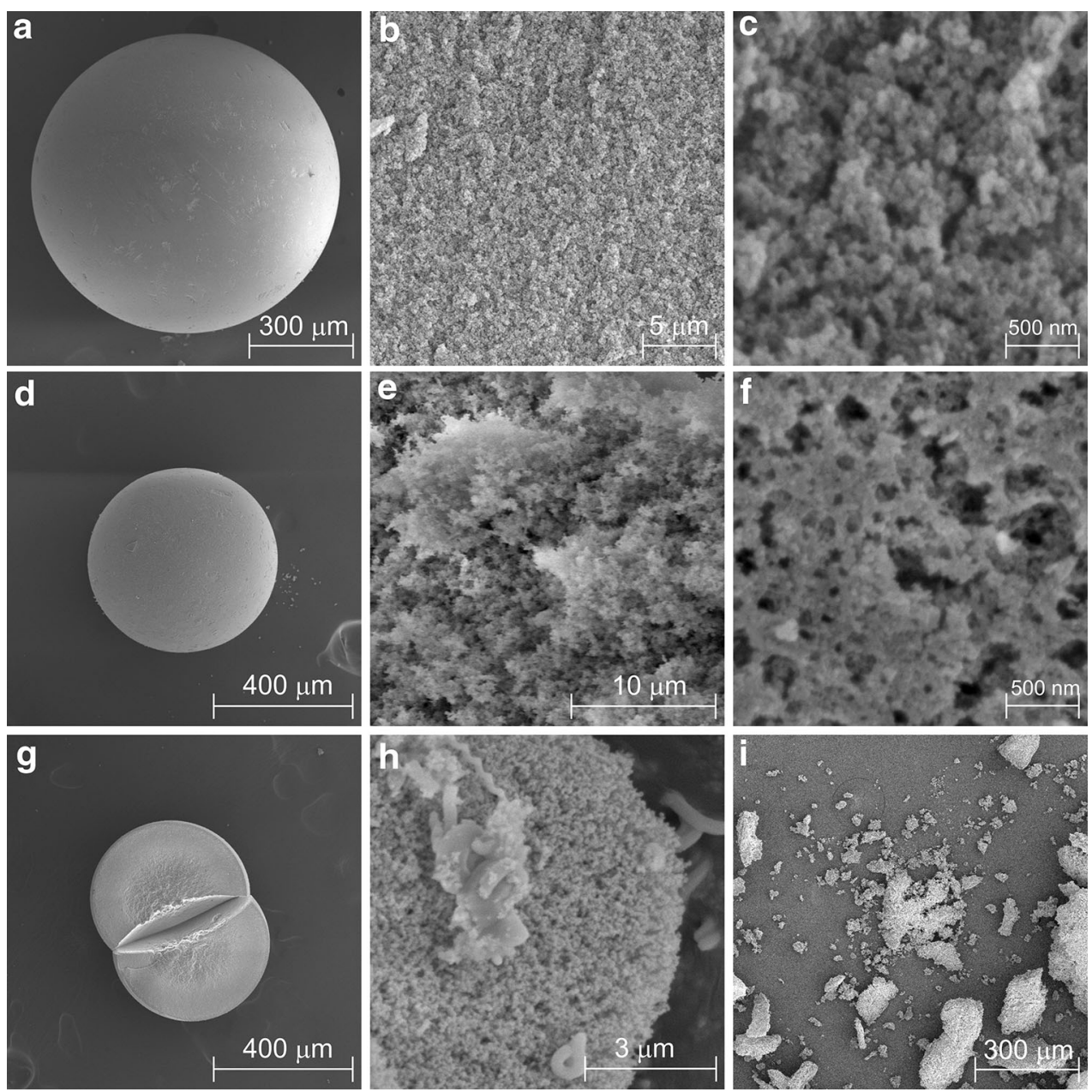

surface. The progress of the exchange reaction is a result of the balance between TBOS-CTAB competition and nucleation of silica species around surfactant micelles in the bulk solution. A part of the silane condenses in the interior of polymer beads and on the outer surface of polymer-CTAB complexes. $n$-butanol produced in the interior of the polymer when hydrolysis of TBOS proceeds probably causes a local saturation of the reacting mixture with $n$-butanol. The increase of the alcohol concentration reduces the further hydrolysis inside polymer pores. This affects the hydrolysis of the remaining, not hydrolyzed part of TBOS. However, the amount of alcohol generated during the hydrolysis of TBOS is small enough to be dissolved totally in the whole aqueous phase. Thus, no additional liquid phase composed of the alcohol is formed in the bulk phase although the miscibility of $n$-butanol in water is only $7.7 \mathrm{wt} \%$ at $20{ }^{\circ} \mathrm{C}$.

The mechanism of the formation of silica structure using polymer template is a complex process because initially the polymer beads saturated with TBOS are nonwettable, and float on the surface of the aqueous solution. After $1 \mathrm{~h}$, when the hydrolysis of TBOS begins and slowly proceeds, the polymer-TBOS beads fall down. This effect is the result of the change of the particle surface character from hydrophobic to hydrophilic. In this way, polymer-silica beads become wettable by the surrounding solution free of the alcohol. Then, the hydrolysis becomes faster again, facilitating the total transformation of TBOS. Simultaneously, with the TBOS hydrolysis and the appearance of surface hydroxyls on the newly produced silica phase, the adsorption of CTAB takes place, which causes the transfer of TBOS into the surrounding solution. Slow desorption of TBOS results in silane being dispersed homogeneously in the bulk solution. Therefore, the nucleation of silica species takes place in the whole solution volume (appearance of the milky phase) at a given concentration of CTAB. From our previous studies on synthesis of silica materials using TEOS as the silica source, it follows that fine particles in the bulk solution out of polymer-silane particles being the product of nucleation appear after about $40 \mathrm{~s}$, whereas when TBOS is used as the silica source the additional phase appears after 3 days. It is worth noticing that, for 
TEOS used as a silica precursor, $40 \mathrm{~s}$ is enough time for adsorption of CTAB and desorption of TEOS, diffusion of TEOS to bulk solution, hydrolysis of TEOS and formation of $\mathrm{SiO}_{2}$ nuclei (Krasucka et al. 2016). For TBOS, this time is much longer, mainly due to a slower hydrolysis rate. In the experiment described above, the formation of small particles in the bulk solution is accompanied by the condensation of silica component on the outer surface of polymer particles. The latter process shows some analogy to the growth of colloidal mesostructured silica nanoparticles. The combination of nucleation and growth processes is of fundamental meaning for regulating the silica nanoparticle formation. These problems are discussed in detail for different silanes in refs. (Kang and Rhee 2005; Yamada et al. 2012, 2015). Our results are in agreement with the findings presented in these papers. Large alkoxy group diminishes the hydrolysis rate of silane. Yamada et al. (2015) showed that the hydrolysis of TBOS needs more than 3 days and it is much longer than TEOS. Additionally, it should be noted that in our experiment, when TBOS is used as the silica source, silica beads are larger than those synthesized with TEOS. This effect is probably caused by smaller shrinkage of the polymer in swollen state during contact with water solution and stiffening of the polymer matrix. As it was mentioned earlier, TBOS condenses at a lower rate inside polymer pores, and $n$-butanol produced during hydrolysis blocks the pore interior, which, in turn, preserves the effective infiltration of the water solution. As a result, a smaller amount of the silica precursor is transferred into the solution. It means that the silica condenses mainly in polymer beads at the expense of nucleation in the bulk solution. The weight proportion of the silica embedded into polymer beads and the silica produced in the bulk solution is as 10:1 and is much lower than in the case of TEOS (3:1).

The infiltration of the polymer with TBOS followed by its transformation to $\mathrm{SiO}_{2}$ creates a new pore system entirely different from the initial polymer. The nitrogen adsorption data presented in Fig. 3a illustrate that the $\mathrm{N}_{2}$ adsorption on the silica derived from the polymer template is substantially elevated in comparison to the initial polymer. Adsorption is very high and the extended hysteresis loop is observed at a higher pressure. The parameters characterizing the porosity of investigated samples derived from nitrogen adsorption/desorption data are collected in Table 1.

The $\mathrm{T}-\mathrm{SiO}_{2}$ sample is characterized by very high specific surface area and the extremely high total pore volume exceeding $2 \mathrm{~cm}^{3}$ per gram. This volume is surprisingly large in comparison to other highly porous silica sorbents, including those of the regular pore structure obtained using templating route. The PSD of $\mathrm{T}-\mathrm{SiO}_{2}$ is of bimodal character and exhibits the presence of two group of pores, the large ones with the peak of PSD centered at $\mathrm{D}_{2}=19 \mathrm{~nm}$, and the smaller ones with the peak centered at $2.5 \mathrm{~nm}$ of narrower PSD.

$\mathrm{X}$-ray diffraction patterns for both discussed silica fractions present non-typical shape and make it possible to exclude the totally amorphous character of these materials (Fig. 4). Although, XRD patterns of $\mathrm{T}-\mathrm{SiO}_{2}$ spheres and MCM-B particles do not possess satisfactorily resolved bands, it seems that they indicate the presence of some regularities in the pore structure of silicas. Indeed, TEM images (Fig. 5) clearly show the presence of uniformly sized parallelly ordered channels in MCM-B of differentiated d-spacing. However, the XRD pattern of MCM-B, which shows three maxima, cannot be ascribed to standard structures of hexagonally ordered mesopores present in MCM-41 or SBA-15 silicas. The small intensity of the Braggs' reflexes is probably a result of the low-range/local ordering of regular pores and it makes the interpretation of the diffractograms very difficult. The rate of ordering is especially restricted for the silica formed inside polymer beads $\left(\mathrm{T}-\mathrm{SiO}_{2}\right)$. Due to the steric reasons, the formation of $\mathrm{CTAB}$ micelles in pores, especially in the narrow ones and in the polymer network, is practically impossible. The
Fig. 3 Nitrogen adsorption (solid points) and desorption (open points) isotherms at $77 \mathrm{~K}$ of XAD7HP (squares), $\mathrm{T}-\mathrm{SiO}_{2}$ (circles) and MCM-B (triangles) (a). The pore size distributions of XAD7HP (solid line), $\mathrm{T}-\mathrm{SiO}_{2}$ spheres (dotted line) and MCM-B (dashed line) (b)
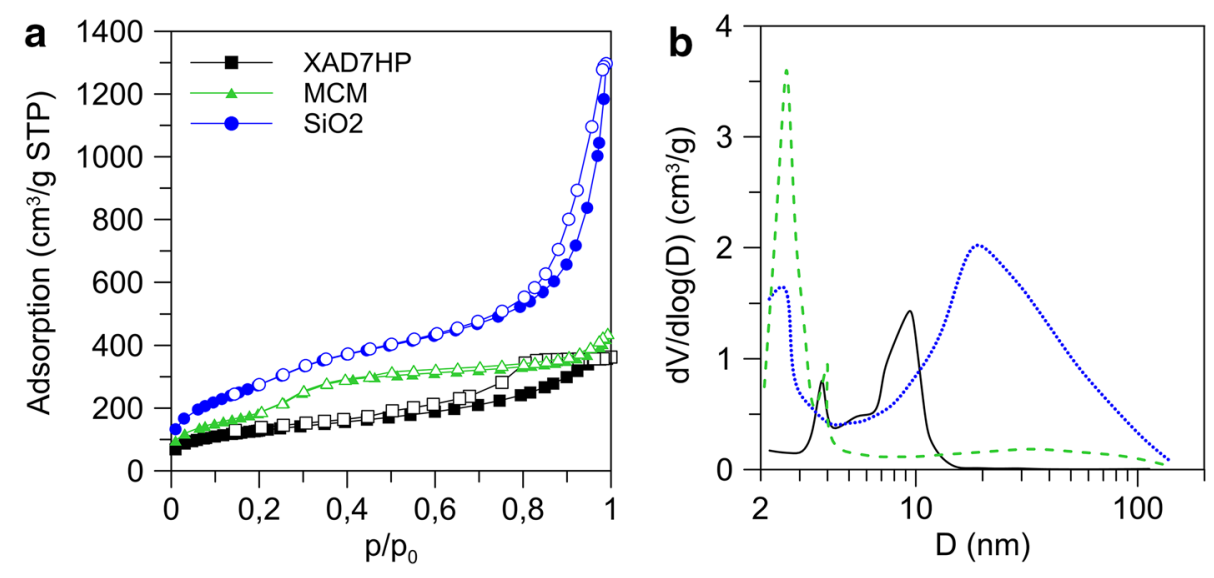
Table 1 The parameters characterizing the porosity of the investigated samples obtained from nitrogen desorption at $77 \mathrm{~K}$ : $\mathrm{S}_{\mathrm{BET}}$ - the specific surface area, $\mathrm{V}_{\mathrm{p}}$ - the total pore volume, $\mathrm{D}_{\mathrm{p}}$ - the pore diameter

\begin{tabular}{lcllc}
\hline Sample & $\mathrm{S}_{\mathrm{BET}}\left(\mathrm{m}^{2} / \mathrm{g}\right)$ & $\mathrm{V}_{\mathrm{p}}\left(\mathrm{cm}^{3} / \mathrm{g}\right)$ & $\mathrm{D}_{\mathrm{p} 1}(\mathrm{~nm})$ & $\mathrm{D}_{\mathrm{p} 2}(\mathrm{~nm})$ \\
\hline XAD7HP & 458 & 0.56 & 3.8 & 9.4 \\
$\mathrm{~T}_{-} \mathrm{SiO}_{2}$ & 1044 & 2.01 & 2.5 & 19.0 \\
$\mathrm{MCM}-\mathrm{B}$ & 725 & 0.68 & 2.6 & 4.0 \\
\hline
\end{tabular}

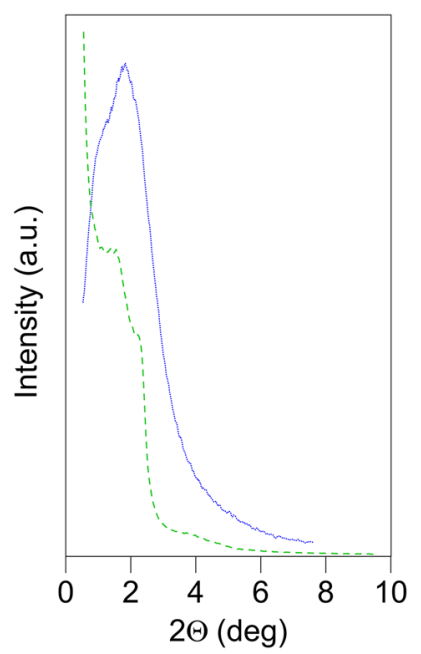

Fig. $4 \mathrm{X}$-ray diffraction patterns of $\mathrm{T}-\mathrm{SiO}_{2}$ (dotted line) and MCM-B (dashed line) siliceous samples

longer range ordering may occur in the more accessible segments of composite beads, i.e. in pore openings, and on the external surface of beads. This hypothesis is proved by successful preparation of ordered silica layers by the templating route on the flat surface of silica support (Nishiyama et al. 2003; Tanaka et al. 2004). However, in the case of a porous matrix, the formation of ordered silica films on its outer surface is less probable. The relatively fast basic hydrolysis of TBOS, faster than in an acid catalyzed process, followed by the condensation of silica species, causes a part of the silica condensation inside polymer pores. Thus, substantial part of the silica precursor is retained within polymer- $\mathrm{SiO}_{2}$ beads. As a result, $\mathrm{T}-\mathrm{SiO}_{2}$ spheres are more densely packed and exhibit exceptionally high porosity.

In the bulk solution, surfactant micelles are surrounded by the $\mathrm{SiO}_{2}$ phase and, as a result, a new siliceous material is formed (MCM-B before calcination). Due to the presence of the surfactant, the regular structure of the MCM-41 type is expected for this silica. Although the fraction of fine MCM-B particles which were formed in the bulk solution out of composite beads shows some kind of pore ordering (Figs. 4, 5), it is not the typical hexagonally arranged pore structure. The PSD of MCM-B (Fig. 3b) is of complex character. The main range of PSD is located at narrow mesopores (bimodal character of PSD), but this silica, besides narrow, uniformly sized pores, additionally contains small number of mesopores of larger diameter up to macropores. The presence of larger mesopores also differentiates this MCM-B silica from a typical MCM-41 material.

The outstanding adsorption capacity of $\mathrm{T}-\mathrm{SiO}_{2}$, confirmed by very high uptake of nitrogen, has been verified by adsorption from binary organic-water solution. As a testing adsorbate, the moderately hydrophobic metronidazole was chosen. Metronidazole is [1-(2-hydroxy-1-ethyl)2-methyl-5-nitroimidazole] (Fig. 6a), a synthetic antibacterial and antiprotozoal drug, the most common representative of the nitroimidazole class. Metronidazole is one of the essential drugs on the WHO list. Unfortunately, beyond high efficiency and high solubility in water, this drug is characterized by low biodegradability, high toxicity and the high ability to bioaccumulate in water. In addition, it was found that this substance is mutagenic and carcinogenic (Ocampo-Perez et al. 2013; Magalhães et al. 2014). Therefore, it is not surprising that many efforts are directed to remove the contamination of metronidazole from the aqueous environment.

Adsorption of metronidazole from aqueous solution makes it possible to verify the adsorption selectivity of the new silica, as well as the degree of hydrophobicity of its surface. Figure 6 shows the adsorption isotherm of metronidazole on the $\mathrm{T}-\mathrm{SiO}_{2}$ silica. For comparative purposes, the adsorption isotherm of the same substance on the commercial silica gel $\mathrm{Si}-40$ is given. Additionally, the empirical Freundlich equation was used to study isotherm of metronidazole adsorption. The correlation coefficients, $\mathrm{R}^{2}$, for the linear form of this isotherm equation equal to 0.995 and 0.998 for the $\mathrm{Si}-40$ and $\mathrm{T}-\mathrm{SiO}_{2}$, respectively. This experiment indicates the strong competition of metronidazole for the $\mathrm{T}-\mathrm{SiO}_{2}$ surface and its noticeable adsorption affinity for the organic. The uptake of metronidazole varies for both silicas even if the extent of adsorption is related to surface concentration expressed per square meter of solids $\left(\mathrm{S}_{\mathrm{BET}} / \mathrm{T}-\mathrm{SiO}_{2}=1044 \mathrm{~m}^{2} / \mathrm{g}, \mathrm{S}_{\mathrm{BET}} /\right.$ $\mathrm{Si}-40=842 \mathrm{~m}^{2} / \mathrm{g}$ ). This is an interesting result, as conventional silica gels exhibit small adsorption of organics, due to the strong competition of water for the silica surface. From our experiment, it follows that adsorption selectivity of $\mathrm{T}-\mathrm{SiO}_{2}$ with reference to the metronidazole is larger than in the case of the Si-40 sample. In terms of the Freundlich relative adsorption capacity, $\mathrm{K}_{\mathrm{f}}$, the value for $\mathrm{T}-\mathrm{SiO}_{2}$ is one order of magnitude larger than for $\mathrm{Si}-40$, and equals $0.0262 \mathrm{mg}^{1-(1 / \mathrm{n})} \mathrm{L}^{1 / \mathrm{n}} \mathrm{g}^{-1}$ and $0.0025 \mathrm{mg}^{1-(1 / \mathrm{n})} \mathrm{L}^{1 / \mathrm{n}} \mathrm{g}^{-1}$, respectively. The $1 / \mathrm{n}$ value is less than unity and equals to 0.982 for $\mathrm{T}-\mathrm{SiO}_{2}$ while this value exceed $1(1 / \mathrm{n}=1.06)$ for $\mathrm{Si}-40$. Thus, one can assume that the surface character of 
Fig. 5 TEM images of the MCM-B particles
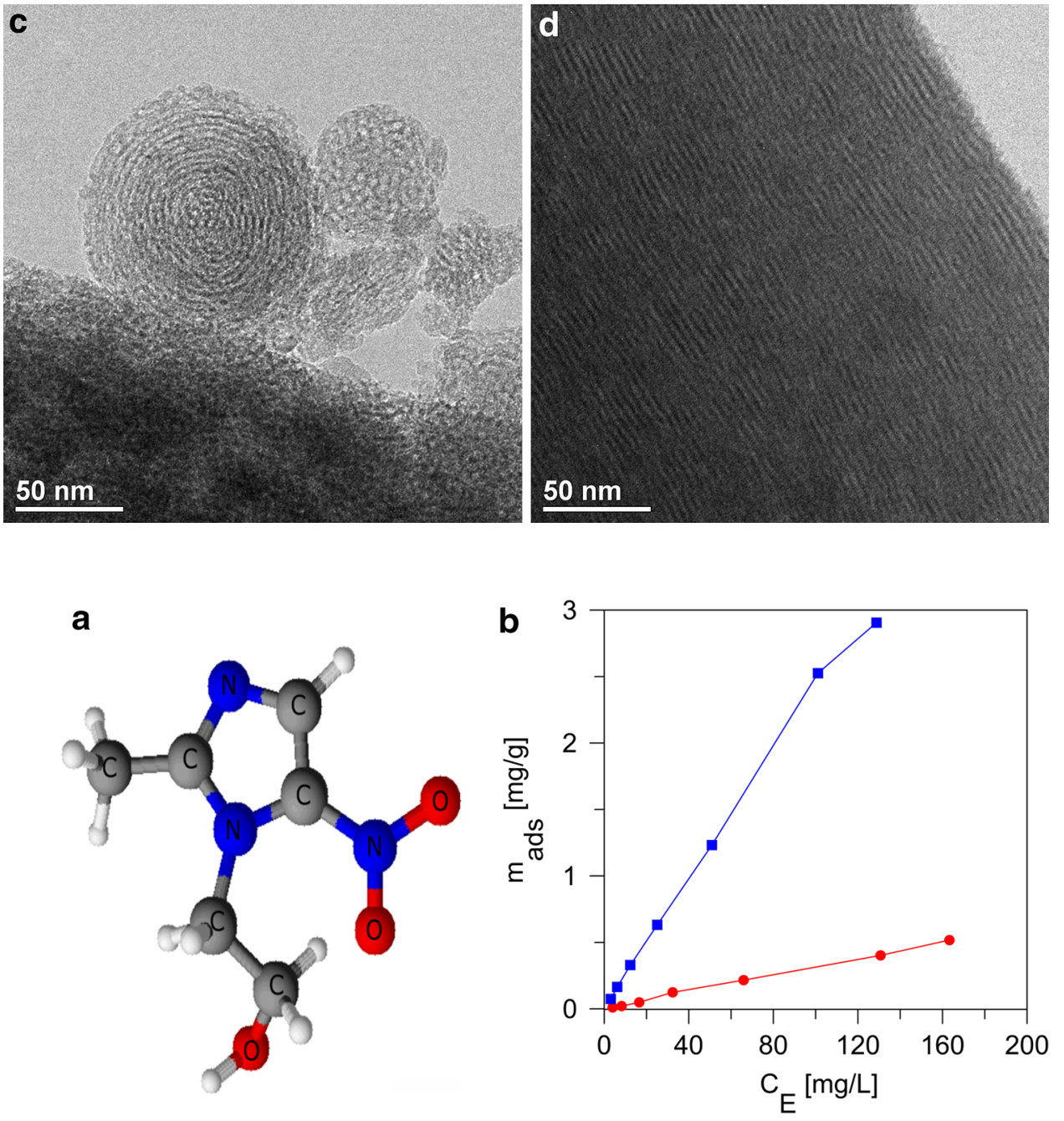
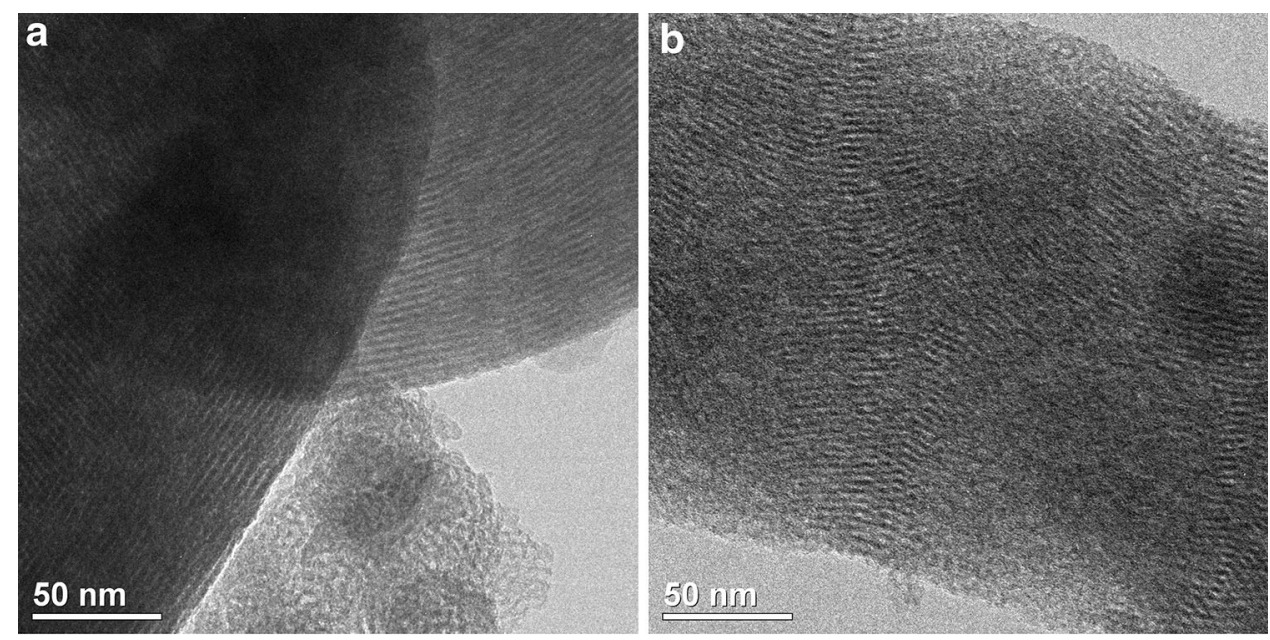

Fig. 6 Representative structure of metronidazole (a) and isotherms of adsorption of metronidazole on $\mathrm{T}-\mathrm{SiO}_{2}$ (squares) and $\mathrm{Si}-40$ (circles) (b) the silica prepared by polymer templating is different. The difference of adsorption for both silicas is the result of their different synthesis route influencing their surface characteristics. In the synthesis of $\mathrm{T}-\mathrm{SiO}_{2}$, the silica condensation takes place in the restricted space of polymer beads.
Additionally, the final material composed of pure $\mathrm{SiO}_{2}$ is obtained by prolonged heating of polymer- $\mathrm{SiO}_{2}$ composite at high temperature in air. These conditions may influence the surface properties of silica 3D structure, as well as the silica surface. One can expect that thermal processing 
Fig. $7{ }^{29} \mathrm{Si} \mathrm{NMR}$ spectra of $\mathrm{T}-\mathrm{SiO}_{2}$ (a) and $\mathrm{Si}-40$ (b) silicas

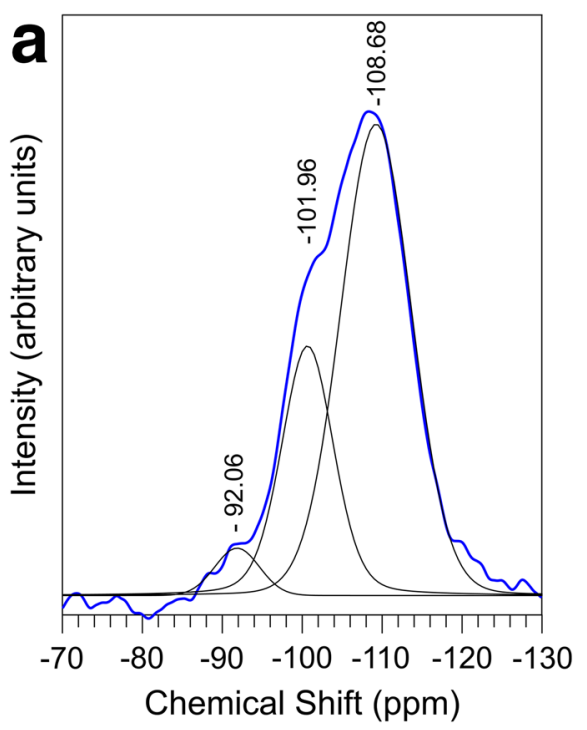

changes the proportion of surface silanols, as compared to the conventional silica gel prepared by sol-gel method. The comparison of the concentration of the surface silanols for $\mathrm{T}-\mathrm{SiO}_{2}$ and $\mathrm{Si}-40$ on the basis of ${ }^{29} \mathrm{Si}$ NMR spectra shown in Fig. 7 confirms this hypothesis.

Deconvoluted spectra of both samples are characterized by well resolved bands at $-90,-100$ and $-110 \mathrm{ppm}$, corresponding to geminal $(-\mathrm{O}-)_{2} \mathrm{Si}(-\mathrm{OH})_{2}$ and isolated $(-\mathrm{O}-)_{3}$ $\mathrm{Si}(-\mathrm{OH})$ silanols $\mathrm{Q}^{2}, \mathrm{Q}^{3}$ and siloxane bridges $(-\mathrm{O}-)_{4} \mathrm{Si}, \mathrm{Q}^{4}$, respectively. However, the proportion of above mentioned species is differentiated. The $\mathrm{SiO}_{2}$ sample contains a smaller number of surface silanols and, consequently, a high concentration of siloxane bridges. The ratio of surface silanols expressed as $\mathrm{Q}^{2}+\mathrm{Q}^{3} / \mathrm{Q}^{4}$ is equal to 0.48 and 0.63 for $\mathrm{T}-\mathrm{SiO}_{2}$ and $\mathrm{Si}-40$, respectively. Thus, dehydroxylation process causes the rise of hydrophobicity of silica surface and, in turn, the higher adsorption of organics.

\section{Conclusions}

Highly porous siliceous samples were prepared using the XAD7HP template. As a silica source, TBOS, characterized by a relatively small hydrolysis rate of alkoxy groups, was used. The silica obtained by calcination of the polymer- $\mathrm{SiO}_{2}$ composite shows the high specific surface exceeding $1000 \mathrm{~m}^{2} / \mathrm{g}$ and the pore volume larger than $2 \mathrm{~cm}^{3}$ and, as a consequence, it exhibits extremely high adsorption capacity towards vapours and gases. Additionally, the new silica obtained by the hard templating route has attractive characteristics because its surface exhibits relatively high adsorption selectivity towards organic substances. In the same synthesis route, besides spherically shaped silica particles, the siliceous material (MCM-B) of the partially regular structure similar to the structure, characteristic for MCM-41, was obtained.

Open Access This article is distributed under the terms of the Creative Commons Attribution 4.0 International License (http://crea tivecommons.org/licenses/by/4.0/), which permits unrestricted use, distribution, and reproduction in any medium, provided you give appropriate credit to the original author(s) and the source, provide a link to the Creative Commons license, and indicate if changes were made.

\section{References}

Acosta, C., Perez-Esteve, E., Fuenmayor, C.A., Benedetti, S., Cosio, M.S., Soto, J., Sancenon, F., Mannino, S., Barat, J., Marcos, M.D., Martinez-Manez, R.: Polymer composites containing gated mesoporous materials for on-command controlled release. ACS. Appl. Mater. Inter. 6, 6453-6460 (2014)

Barrett, E.P., Joyner, L.G., Halenda, P.P.: The determination of pore volume and area distributions in porous substances. I. Computations from nitrogen isotherms. J. Am. Chem. Soc. 73, 373-380 (1951)

Beck, J.S., Vartuli, J.C., Roth, W.J., Leonowicz, M.E., Kresge, C.T., Schmitt, K.D., Chu, C.T.W., Olson, D.H., Sheppard, E.W., McCullen, S.B., Higgins, J.B., Schlenker, J.L.: A new family of mesoporous molecular sieves prepared with liquid crystal templates. J. Am. Chem. Soc. 114, 10834-10843 (1992)

Bogush, G.H., Tracy, M.A., Zukoski, C.F.: Preparation of monodisperse silica particles: control of size and mass fraction. J. NonCryst. Solids 104, 95-106 (1988)

Chang-Chien, C.Y., Hsu, C.H., Lin, H.P., Tang, C.Y., Lin, C.Y.: Synthesis of porous carbon and silica spheres using PEO-PF polymer blends. J. Porous Mat. 13, 195-199 (2006)

Fuchigami, K., Taguchi, Y., Tanaka, M.: Synthesis of spherical silica particles by sol-gel method and application. Polym. Advan. Technol. 19, 977-983 (2008)

Kang, K.K., Rhee, H.K.: Synthesis and characterization of novel mesoporous silica with large wormhole-like pores: use of TBOS as silicon source. Microporous Mesoporous Mater. 84, 34-40 (2005) 
Kierys, A., Dziadosz, M., Goworek, J.: Polymer/silica composite of core-shell type by polymer swelling in TEOS. J. Colloid. Interf. Sci. 349, 361-365 (2010)

Kierys, A., Rawski, M., Goworek, J.: Polymer-silica composite as a carrier of an active pharmaceutical ingredient. Microporous Mesoporous Mater. 193, 40-46 (2014)

Krasucka, P., Stefaniak, W., Kierys, A., Goworek, J.: Polymer-silica composites and silicas produced by high-temperature degradation of organic component. Thermochim. Acta 615, 43-50 (2015)

Krasucka, P., Stefaniak, W., Kierys, A., Goworek, J.: One-pot synthesis of two different highly porous silica materials. Microporous Mesoporous Mater. 221, 14-22 (2016)

Kwon, S., Singh, R.K., Perez, R.A., Abou Neel, E.A., Kim, H.W., Chrzanowski, W.: Silica-based mesoporous nanoparticles for controlled drug delivery. J. Tissue Eng. 4, 2041731413503357 (2013). doi:10.1177/2041731413503357

Magalhães, S.M.S., Brêtas, C.M., Brêtas, J.M., Pianetti, G.A., Franco, M.W., Barbosa, F.A.R.: Toxic concentrations of metronidazole to Microcystis protocystis. Braz. J. Biol (2014). doi:10.1590/ 1519-6984.03513

Menon, V.C., Komarneni, S.: Porous adsorbents for vehicular natural gas storage: a review. J. Porous Mat. 5, 43-58 (1998)

Nejat, R., Mahjoub, A.R., Hekmatian, Z., Azadbakht, T.: Pdfunctionalized MCM-41 nanoporous silica as an efficient and reusable catalyst for promoting organic reactions. Rsc Adv. 5, 16029-16035 (2015)

Nishiyama, N., Tanaka, S., Egashira, Y., Oku, Y., Ueyama, K.: Vapor-phase synthesis of mesoporous silica thin films. Chem. Mater. 15, 1006-1011 (2003)

Ocampo-Perez, R., Orellana-Garcia, F., Sanchez-Polo, M., RiveraUtrilla, J., Velo-Gala, I., Lopez-Ramon, M.V., Alvarez-Merino, M.A.: Nitroimidazoles adsorption on activated carbon cloth from aqueous solution. J. Colloid. Interf. Sci. 401, 116-124 (2013)

Rahman, I.A., Vejayakumaran, P., Sipaut, C.S., Ismail, J., Bakar, M.A., Adnan, R., Chee, C.K.: An optimized sol-gel synthesis of stable primary equivalent silica particles. Colloid Surf. A 294(1), 102-110 (2007)

Ramachandran, S., Ha, J.H., Kim, D.K.: Hydrogen storage characteristics of metal oxide doped Al-MCM-41 mesoporous materials. Catal. Commun. 8, 1934-1938 (2007)

Sepehrian, H., Waqif-Husain, S., Ghannadi-Maragheh, M.: Development of thiol-functionalized mesoporous silicate MCM-41 as a modified sorbent and its use in chromatographic separation of metal ions from aqueous nuclear waste. Chromatographia 70, 277-280 (2009)

Stober, W., Fink, A., Bohn, E.: Controlled growth of monodisperse silica spheres in the micron size range. J. Coll. Interf. Sci. 26, 62-69 (1968)

Tanaka, S., Nishiyama, N., Oku, Y., Egashira, Y., Ueyama, K.: Nanoarchitectural silica thin films with two-dimensionally connected cagelike pores synthesized from vapor phase. J. Am. Chem. Soc. 126, 4854-4858 (2004)

Udayakumar, S., Pandurangan, A., Sinha, P.K.: Mesoporous material as catalyst for the production of fine chemical: synthesis of dimethyl phthalate assisted by hydrophobic nature MCM-41. J. Mol. Catal. A Chem. 240, 139-154 (2005)

Vallet-Regi, M., Balas, F., Arcos, D.: Mesoporous materials for drug delivery. Angew. Chem. Int. Ed. Engl. 46, 7548-7558 (2007)

Yamada, H., Urata, C., Aoyama, Y., Osada, S., Yamauchi, Y., Kuroda, K.: Preparation of colloidal mesoporous silica nanoparticles with different diameters and their unique degradation behavior in static aqueous systems. Chem. Mater. 24, 1462-1471 (2012)

Yamada, H., Urata, C., Yamamoto, E., Higashitamori, S., Yamauchi, Y., Kuroda, K.: Effective use of alkoxysilanes with different hydrolysis rates for particle size control of aqueous colloidal mesostructured and mesoporous silica nanoparticles by the seedgrowth method. Chem. Nano. Mat. 1, 194-202 (2015) 